\title{
OBTENÇÃo DE NOVA FONTE DE PEROXIDASE DE FOLHA DE Copaifera langsdorffii DESF. COM ALTA ATIVIDADE ${ }^{1}$
}

\author{
Hermelinda Penha Freire MACIEL ${ }^{2}$, Cibele Marli Cação Paiva GOUVÊA ${ }^{3, *}$, Gláucia Maria PASTORE ${ }^{2}$
}

\begin{abstract}
RESUMO
Objetivou-se neste trabalho extrair peroxidase de folha de Copaifera langsdorffii (COP), medir sua atividade, compará-la com a peroxidase de raiz forte (Horseradish peroxidase - HRP) e determinar o pH ótimo, a melhor solução extratora e o efeito de aditivos sobre a atividade da COP. Os resultados mostraram que a COP atingiu 81,6\% da atividade de HRP e a faixa de $\mathrm{pH}$ ótimo foi de 5,5 a 6,0. A melhor solução extratora da enzima foi o tampão fosfato de sódio $50 \mathrm{mM}$, pH 6,0 e o melhor aditivo foi o PVPP. Concluindo, a COP apresenta atividade mais alta que outras peroxidases de diferentes fontes citadas na literatura.

Palavras-chave: Copaifera langsdorffii, peroxidase, atividade enzimática, horseradish peroxidase, extrato vegetal.
\end{abstract}

\section{SUMMARY}

OBTENTION OF A NEW SOURCE OF PEROXIDASE FROM Copaifera langsdorffii LEAF, Desf. WITH HIGH ACTIVITY. The purpose of this work was to extract peroxidase from Copaifera langsdorffii leaves (COP), measure its activity, compare it to that of Horseradish peroxidase and determine the optimum $\mathrm{pH}$, the best extraction solution and the effect of additives on the COP activity. The results showed that COP has $81.6 \%$ of the activity of HRP and an optimum pH range between 5.5-6.0. The best extraction solution was a sodium phosphate buffer $50 \mathrm{mM}, \mathrm{pH} 6.0$ and the best additive was PVPP. In conclusion, COP presents higher activity than peroxidases from different sources reported in the literature.

Keywords: Copaifera langsdorffii, peroxidase, enzyme activity, horseradish peroxidase, vegetal extract.

\section{1 - INTRODUÇÃO}

As peroxidases de plantas (E.C. 1.11.1.7) têm atraído, consideravelmente, o interesse de pesquisadores, pelo envolvimento dessas enzimas em diversas reações biológicas, como: reações de oxidação, processos de diferenciação celular, crescimento, controle de funções metabólicas e resistência a patógenos [15, 30,36]. As peroxidases também estão envolvidas na polimerização de fenil propanóides, que iniciam a síntese de lignina, flavonóides e outros compostos fenólicos [6], alguns com atividade antioxidante, como os flavonóides, podem prevenir o envelhecimento celular [17].

A capacidade de ligação específica a anticorpos ou outras proteínas, torna amplo o uso da peroxidase em kits diagnósticos laboratoriais de interesse médico [34]. Elas podem ser usadas como biossensores em análises clínicas e avaliação do conteúdo de ácido L-ascórbico em formulações farmacêuticas [12]. São úteis em várias atividades de pesquisa laboratorial, como determinação de microrganismos patogênicos [10], toxinas [11] e ensaios de higiene de alimentos [9]. Métodos de diagnósticos têm sido desenvolvidos usando peroxidases por médicos dermatologistas,

\footnotetext{
${ }^{1}$ Recebido para publicação em 16/11/2004. Aceito para publicação em 6/7/2006 (001439)

${ }^{2}$ Faculdade de Engenharia de Alimentos,

Universidade Estadual de Campinas (UNICAMP),

C. P. 6.121, CEP 13083-970, Campinas (SP)

${ }^{3}$ Departamento de Ciências Biológicas,

Universidade Federal de Alfenas (UNIFAL-MG),

CEP 37130-000, Alfenas (MG)

E-mail: cibelegouvea@hotmail.com

* A quem a correspondência deve ser enviada
}

para avaliar e monitorar o tratamento em processos como psoríase e câncer de pele, bem como quantificação de níveis de radicais livres no sangue [33]. A peroxidase ligada pode ser revelada através de reação com $\mathrm{H}_{2} \mathrm{O}_{2}$, na presença de vários doadores de $\mathrm{H}^{+}$, como o guaiacol, que se oxida desenvolvendo um composto colorido, o tetraguaiacol, que pode ser medido por espectrofotometria [24].

$\mathrm{Na}$ indústria de alimentos, a peroxidase pode ser usada na determinação de testes de autenticidade de alimentos [4] e na determinação quantitativa de glicose $[8,28]$. Vários constituintes de alimentos são identificados pela propriedade das peroxidases se ligarem a diferentes doadores de $\mathrm{H}^{+}$[5] Devido à alta estabilidade e fácil detecção, estas enzimas são as mais usadas para determinar se o processamento de vegetais pelo calor foi adequado [2].

No meio ambiente, o índice de poluição de águas pode ser avaliado através de testes utilizando peroxidases [14, 18] e ainda a diminuição de resíduos poluentes de indústria de tecidos, que utilizam estas enzimas em processos de descoloração, evitando a formação de compostos tóxicos [29].

Muitos procedimentos têm sido propostos na literatura para a obtenção de peroxidases, bem como o desenvolvimento de métodos, para extração, utilizando técnicas simplificadas e equipamentos de menor custo operacional $[12,19,23]$.

A fonte comercial mais utilizada de peroxidase é a raiz forte, que é geralmente cultivada e colhida em países de clima frio. Assim, novas fontes de peroxidases precisam ser obtidas, para atender a crescente demanda desta enzima. A Copaífera langsdorffii é uma árvore leguminosa, nativa e amplamente distribuída no território brasileiro, com pro- 
dução abundante de folhas durante todo o ano. O objetivo deste trabalho foi extrair peroxidase de folhas de Copaifera langsdorffii (COP), medir sua atividade e compará-la a HRP, extraída em condições idênticas. Também foram determinados a faixa de pH ótimo, a solução extratora mais adequada e o efeito de aditivos sobre a atividade da COP.

\section{2 - MATERIAL E MÉTODOS}

\section{1 - Tecido fonte de peroxidases}

\subsection{1 - COP}

Folhas de Copaifera langsdorffii foram colhidas de árvores do câmpus da Unicamp, pela manhã (até as 9 h). As folhas foram lavadas em $\mathrm{H}_{2} \mathrm{O}$ destilada, secas com papel absorvente e em seguida submetidas à extração de peroxidase (COP).

\subsection{2 - HRP}

Raiz de Armoracia rusticana, conhecida como raiz ardida, raiz forte, rábano de cavalo ou rábano rusticana, foi obtida do cultivo do sítio Nosso Recanto, Estrada de Vila Élvio, Piedade (SP). A raiz foi lavada e, após divisão em partes menores, foi submetida à extração de peroxidase (HRP).

\section{2 - Obtenção da peroxidase das duas fontes}

Para avaliação da atividade da peroxidase de folhas de C. langsdorffii (COP), como nova fonte desta enzima, foi realizada extração de acordo com procedimento descrito por JACKSON \& RICARDO [20], com modificações. As folhas de C. langsdorffii foram pesadas para trituração, na proporção de $1 \mathrm{~g}$ de folha para $4 \mathrm{~mL}$ (p/v) de tampão Tris-HCl $50 \mathrm{mM}$, pH 7,2 gelado (solução extratora). A amostra foi então colocada em liquidificador para homogeneização por 5 min, em baixa rotação. Em seguida, o homogeneizado foi filtrado em gaze com malha reduzida por 6 dobras, sendo o filtrado recolhido em banho de gelo e centrifugado a $11.000 \times \mathrm{g}$, a $5{ }^{\circ} \mathrm{C}$, por 15 min. $\mathrm{O}$ sobrenadante foi submetido à medida de atividade da COP. Procedeu-se também a extração de peroxidase da raiz forte (HRP). A raiz foi dividida em partes menores e submetida ao mesmo procedimento descrito para obtenção da COP.

\section{3 - Determinação da atividade de peroxidase}

A atividade foi determinada segundo KHAN \& ROBINSON [22]. Uma unidade de enzima (U) foi definida como a atividade que causa aumento de 0,001 unidades de absorbância.min ${ }^{-1}$ a $470 \mathrm{~nm}$ a $25^{\circ} \mathrm{C}$, usando-se como meio de reação: $1,5 \mathrm{~mL}$ de guaiacol $1 \%(\mathrm{v} / \mathrm{v}) ; 0,4 \mathrm{~mL}$ de $\mathrm{H}_{2} \mathrm{O}_{2} 0,3 \%(\mathrm{v} / \mathrm{v})$ ou $0,1 \mathrm{M}$; $0,1 \mathrm{~mL}$ de enzima (mantida em banho de gelo) e 1,2 mL de tampão fosfato de sódio 50 mM, pH 6,0.

\section{4 - Influência da solução extratora na atividade da COP}

Este processo foi realizado para determinar a solução extratora que fornece melhor atividade enzimática. A extração de peroxidase foi realizada conforme descrito no item 2.2 e foram utilizados: tampão fosfato de sódio $50 \mathrm{mM}$, pH 6,0, $\mathrm{H}_{2} \mathrm{O}$ destilada e tampão Tris- $\mathrm{HCl} 50$ mM, pH 7,2 como soluções extratoras. Foram feitas três repetições para cada extração.

\section{5 - Determinação do pH ótimo de atividade da COP}

Utilizando-se a solução extratora de maior atividade, foi determinada a faixa de $\mathrm{pH}$ ótimo. Para tanto se adicionaram $0,1 \mathrm{~mL}$ de enzima em meio de reação contendo $1,5 \mathrm{~mL}$ de guaiacol $1 \%(\mathrm{v} / \mathrm{v}) ; 0,4 \mathrm{~mL}$ de $\mathrm{H}_{2} \mathrm{O}_{2} 0,3 \%(0,1 \mathrm{M})$ e $1,5 \mathrm{~mL}$ de ácido succínico $0,1 \mathrm{M}$ com valores de $\mathrm{pH}$ de 3,0-7,0, com variação de 0,5 unidades.

\section{6 - Influência de aditivos na atividade da COP}

Utilizando-se a solução extratora de maior atividade foi feita a incorporação de aditivos, para avaliar-se a influência na atividade enzimática, de acordo com método de Holschuh [16]. Foram utilizados $\mathrm{NaCl} \mathrm{0,2} \mathrm{M} ; \mathrm{KCl} \mathrm{0,2} \mathrm{M} ; \mathrm{CaCl}_{2}$ $0,2 \mathrm{M}, \mathrm{PEG}$ (polietilenoglicol) a $2 \%(\mathrm{v} / \mathrm{v})$, PVPP (polivinil polipirrolidona) a $2 \%(\mathrm{p} / \mathrm{v})$ e EDTA $10 \mathrm{mM}$, os quais foram incorporados ao tampão fosfato de sódio $50 \mathrm{mM} \mathrm{pH} \mathrm{6,0.}$ Em todas as etapas de extração foi medida a atividade, conforme descrito no item 2.3. Foram feitas 3 repetições para cada tratamento.

\section{7 - Análise estatística}

Os dados obtidos para os experimentos realizados foram expressos como média \pm erro padrão e foram comparados por teste t-Student ou por análise de variância pelo teste ANOVA, seguido do teste de Tukey-Kramer, quando $\mathrm{p}<0,05$.

\section{3 - RESULTADOS E DISCUSSÃO}

\section{1 - Obtenção do extrato bruto}

A peroxidase de folhas de Copaifera langsdorffii (COP) apresentou alta atividade $(81,6 \%)$ quando comparada à atividade do extrato bruto de peroxidase de raiz forte (HRP), obtidas nas mesmas condições. A peroxidase de folhas de Copaifera langsdorffii e raiz forte apresentaram atividade de $19.920 \pm 60$ e $24.410 \pm 53 \mathrm{U} / \mathrm{mL}$ respectivamente. A análise pelo teste $t$ não mostrou diferença significativa $(p=0,07)$ entre a atividade das enzimas.

Os resultados comparativos, entre as atividades das duas enzimas, indicaram alta atividade da enzima extraída de folhas C. langsdorffii (COP). A atividade da COP foi mais 
alta que a descrita para outras plantas tais como: uva [7,32], carambola [16], morango [27] e tremoço [31].

\section{2 - Influência da solução extratora na atividade da COP}

Diferentes soluções para extração de peroxidase têm sido descritas na literatura, destacando-se: tampão Tris-HCl 50 mM, pH 7,2 [20], água destilada [26], tampão Tris- $\mathrm{HCl}$ contendo $\mathrm{CaCl}_{2}$ e ácido ascórbico [27].

A atividade da COP mostrou diferença significativa pelo teste de Tukey-Kramer $\left(\mathrm{p}<10^{-3}\right)$, dependente da solução extratora. Foi obtida maior atividade com o tampão fosfato de sódio $50 \mathrm{mM}$, pH 6,0 (73.146 $\pm 5.213 \mathrm{U} / \mathrm{mL})$, seguida da extração com água (60.935 $\pm 4.716 \mathrm{U} / \mathrm{mL})$ e com Tris-HCl 50 mM, pH 7,2 (24.820 196 U/mL).

\section{3 - pH ótimo de atividade da COP}

A atividade da COP mostrou variação significativa ( $\mathrm{p}<0,001$ ) em função do pH. A COP apresentou atividade ótima na faixa de pH 5,5 - 6,0 (Figura 1).

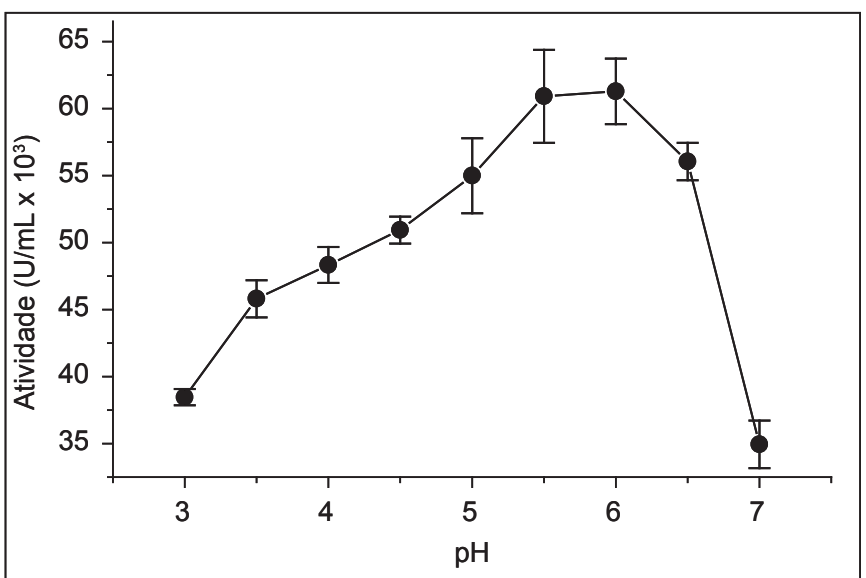

FIGURA 1 - Efeito do pH sobre atividade de peroxidase de folhas de Copaifera langsdorffi (COP).

A variação de $\mathrm{pH}$ determinou diferença da atividade de COP, com valores semelhantes aos obtidos por outros autores [25,26]. Em pH ácido a COP apresentou diminuição de atividade. Essa diminuição da atividade pode ter ocorrido principalmente por alterações químicas no grupo heme da enzima ou desnaturação protéica. Isto também foi observado por ADAMS [1], em um estudo da regeneração e cinética da inativação de HRP. A COP apresentou baixa atividade em valores de $\mathrm{pH}$ iguais ou superiores a 7,0 e também em $\mathrm{pH} 3,0$ a $25^{\circ} \mathrm{C}$.

\section{4 - Influência de aditivos na atividade da COP}

Ocorreu variação significativa $(\mathrm{p}<0,05)$ da atividade da COP sob a influência de aditivos. O PVPP $2 \%$ induziu o maior aumento da atividade da COP, seguido do $\mathrm{NaCl}$ 0,2 M, $\mathrm{CaCl}_{2}$ 0,2 M e PEG 2\%. A adição de $\mathrm{KCl}$ 0,2 M e EDTA 10 mM provocou diminuição da atividade enzimática (Figura 2).

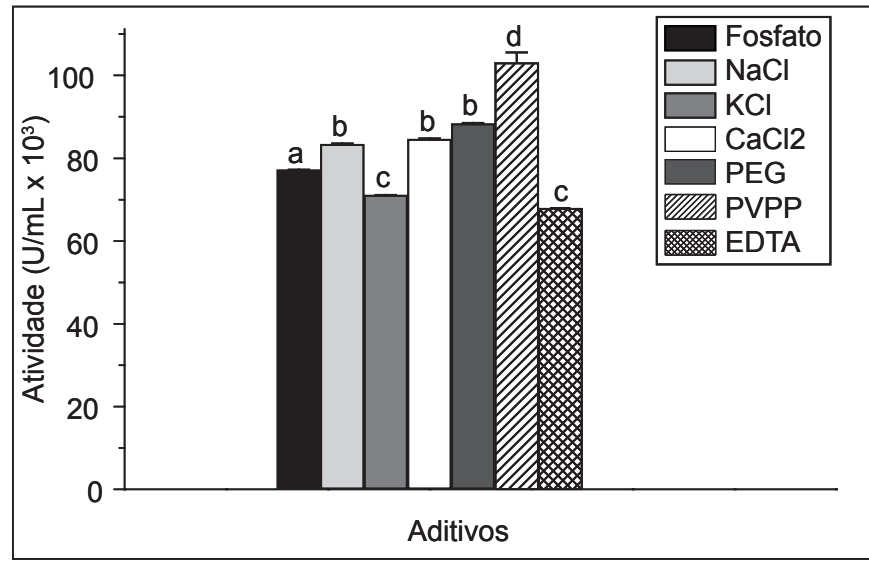

FIGURA 2 - Influência dos aditivos sobre a atividade de peroxidase de folhas de Copaifera langsdorffii (COP). Letras diferentes indicam diferença significativa $(\mathrm{p}<0,05)$, pelo teste de Tukey-Kramer.

Os resultados do presente trabalho indicam que, embora tenha ocorrido aumento significativo da atividade de COP com alguns aditivos, especialmente com PVPP a $2 \%$, a atividade apenas com tampão fosfato foi alta. Diversos trabalhos descrevem um melhoramento significativo na atividade e estabilidade de enzimas, quando o procedimento de extração é realizado em presença de aditivos [35]. Os aditivos têm sido utilizados para proteção da inativação da enzima, retenção da camada de água ao redor do biocatalisador e como dipersantes das moléculas da enzima e facilitadores de transporte de massa. O contato do aditivo com a enzima pode apresentar comportamento antagônico, isto é, a interação pode apresentar um efeito negativo na reação de interesse. Nem todos os aditivos são eficientes como estabilizantes e a influência do aditivo na atividade enzimática ainda não está totalmente esclarecida [35].

A seleção do aditivo adequado é função do tipo de enzima. No caso de enzimas, que exigem uma interface para sua total atividade catalítica, o uso de aditivos macromoleculares tem mostrado efeitos estabilizantes significativos, por meio do revestimento da interface impedindo, desta forma, uma mudança de sua estrutura protéica. No presente trabalho foi demonstrado que o PVPP foi o melhor aditivo para a COP. Outro parâmetro que também interfere na eficiência de um determinado aditivo é referente à sua forma de adição no procedimento de extração enzimática, ou seja, em que etapa esta adição é mais indicada e qual a massa de aditivo necessária para promover uma estabilização satisfatória. Com relação ao primeiro fator, tem sido sugerido que a adição de aditivos seja efetuada antes da extração de enzima ou simultaneamente com a enzima. Neste trabalho os aditivos foram adicionados ao tampão antes da extração enzimática, pois têm sido demonstrado que a adição de 
aditivos depois da enzima ter sido extraída não apresenta efeito benéfico. Quanto à massa de aditivo, recomenda-se uma avaliação experimental em função do tipo de aditivo usado, tendo em vista que o efeito do aditivo depende de sua massa molecular [35]. Os aditivos têm sido também utilizados para observar a variação da atividade, como investigação adicional do comportamento enzimático [16] ou para acentuar baixa atividade de enzimas, como utilizada por LOPES- SERRANO \& ROS BARCELÓ [27] para calcular a inativação da peroxidase de morango.

\section{4 - CONSIDERAÇÕES}

A peroxidase tem sido usada como enzima apropriada para o preparo de imunoconjugados, imunoensaios (ELISA) e técnicas de hibridização não-radioisotópica para investigação de ácidos nucléicos [29]. Assim a utilização da COP no preparo desses reagentes pode trazer vantagens práticas, com a potencial facilidade da produção desta enzima em escala comercial.

Outra importante aplicação de peroxidase é a sua utilização em exames clínicos, associada a outras enzimas como agente sensitivo, envolvendo catálise por oxidase, numa variedade de análises de interesse médico [3]. A oxidação de substrato por oxidase específica, fornece produto estequiométrico da quantidade de peróxido de hidrogênio contido ou produzido numa amostra, a partir de compostos presentes nesta amostra em análise. O peróxido de hidrogênio então, serve para oxidar um agente cromogênico, doador de hidrogênio, cuja formação colorida pode ser medida por espectrofotometria. A glicose do sangue e colesterol do plasma podem ser determinados com glicose oxidase e colesterol oxidase respectivamente, de acordo com este princípio.

O sistema oxidase/peroxidase pode ser também analisado eletroquimicamente. Isto pode ocorrer por determinação amperométrica, como no caso de D-aminoácidos, usando-se biossensor, através de eletrodo de pasta de carbono, quimicamente co-imobilizado com peroxidase e D-aminoácido oxidase [21].

Desta forma, como as peroxidases de outras fontes podem ser usadas para estes propósitos, a COP precisa ser avaliada quanto a sua aplicabilidade. A extração simples de COP resultará em vantagem econômica, como baixo custo de produção, sem a necessidade do desenvolvimento de plantas transgênicas, como proposto por alguns autores [13]. Uma importante vantagem da C.langsdorffii como fonte de COP é a abundância das folhas durante todo ano, sendo ainda amplamente distribuída em todo o país, quer seja na forma nativa ou de reflorestamento, o que pode garantir o fácil acesso para produção de peroxidase em grande escala.

\section{5 - CONCLUSÕES}

Os resultados obtidos indicam que a folha de Copaifera langsdorffii, pode ser uma nova fonte de peroxidase (COP) com alta atividade. O método de extração da peroxidase proposto neste trabalho, mostrou ser simples e economicamente viável, o que possibilita contribuir para a obtenção de peroxidase em alta escala e baixo custo. A faixa de $\mathrm{pH}$ ótimo da COP foi entre 5,5 e 6,0; a melhor solução extratora da COP foi o tampão fosfato $50 \mathrm{mM} \mathrm{pH} \mathrm{6,0} \mathrm{e} \mathrm{o} \mathrm{melhor}$ aditivo foi o PVPP.

\section{6 - REFERÊNCIAS BIBLIOGRÁFICAS}

[1] ADAMS, J. B. Regeneration and the kinetics of peroxidase inactivation. Food Chemistry, v. 60, n. 2, p. 201-206, 1997.

[2] ____ Review: Enzyme inactivation during heat processing of food-stuffs. International Journal of Food Science and Technology, v. 26, n. 1, p. 1-20, 1991.

[3] ALLAIN, C. C.; POON, L. S.; CHAN, C. S. G.; RICHMOND, W. R.; FU, P. C. Enzymatic determination of total serum cholesterol. Clinical Chemistry, v. 20, n. 4, p. 470-475, 1974.

[4] ANGUITA, G.; MARTÍN, R.; GARCÍA,T.; MORALES, P.; HAZA, A. I.; GONZÁLEZ, I.; SANZ, B.; HERNÁNDEZ, P. E. A competitive enzyme-linked immunosorbent assay for detection of bovine milk in ovine and caprine milk and cheese using a monoclonal antibody against bovine-casein. Journal of Food Protection, v. 60, n. 1, p. 64-66, 1997.

[5] ARNAO, M. B.; CANO, A.; HERNÁNDEZ-RUIZ, J.; GARCÍA-CÁNOVAS, F.; ACOSTA, M. Inhibition by Lascorbic acid and other antioxidants of the 2-2'-azidobis (3-ethylbenzothiazoline-6-sulfonic acid) oxidation catalyzed by peroxidase: A new approach for determining total antioxidant status of foods. Analytical Biochemistry, v. 236, n. 2, p. 255-261, 1996.

[6] BAUCHER, M.; CHRISTENSEN, J. H.; MEYERMANS, H.; CHEN, C.; VAN DOORSSELAERE, J.; LEPLÉ, J. C.; PILATE, G.; PETIT-CONIL, M.; JOUANIN, L.; CHABBERT, B.; MONTIES, B.; VAN MONTAGU, M.; BOERJAN, W. Applications of molecular genetics for biosynthesis of novel lignins. Polymer Degradation and Stability, v. 59, n. 1-3, p. 47-52, 1998.

[7] CALDERÓN, A. A.; ZAPATA, J. M.; MUÑOZ, R.; ROS BACELÓ, A. Localization of peroxidase in grapes using nitro-cellulose blotting of freezing/thawing fruits. HortScience, v. 28, n. 1, p. 38-40, 1993.

[8] CASElla, L.; GUllotti, M.; NARCheSini, A.; PETRARULO, M. Rapid enzymatic method for vitamin $\mathrm{C}$ assay in fruits and vegetables using peroxidase. Journal of Food Science, v. 54, n. 2, p. 374-375, 378, 1989.

[9] CHANG, T.; HUANG, S. H. An enzyme-linked immunosorbent assay for the rapid detection of Staphylococcus aureus in processed foods. Journal of Food Protection, v. 57, n. 2, p. 184-189, 1994.

[10] CHEN, C. H.; CHANG, T. C. An enzyme-linked immunosorbent assay for the rapid detection of Vibrio parahaemolyticus. Journal of Food Protection, v. 58, n. 8, p. 873-878, 1995.

[11] CHU, F. S.; FAN, T. S. L. Indirect enzyme-linked immunsorbent assay for saxitoxin in shellfish. Journal of AOAC International, v. 68, n. 1, p. 13-16, 1985.

[12] FATIBELLO-FILHO, O.; VIEIRA, I. C. L-ascorbic acid determination in pharmaceutical formulations using a biosensor based on carbon paste modified with crude 
extract of Zucchini (Cucurbita pepo). Journal Brazilian Chemical Society, v. 11, n. 4, p. 412-418, 2000.

[13] GAZARYAN, I. G.; LAGRIMINI, L. M. Purification and unusual kinetic properties of a tobacco anionic peroxidase. Phytochemistry, v. 41, n. 4, p. 1029-1034, 1996.

[14] GLAZE, W. H. Reaction products of ozone: a review. Environmental Science and Technology, v. 21, n. 3, p. 224-227, 1987.

[15] HAMMERSCHMIDT, R.; NUCKLES, E.; KERE, J. Association of enhanced peroxidase activity in induced systemic resistance of cucumber to Colettotrichum lagenarium. Physiology Plant Pathology, v. 20, n. 1, p. 73-82, 1982.

[16] HOLSCHUH, H. J. Isolamento, purificação e caracterização bioquímica de peroxidase da carambola (Averrhoa carambola, L.). Campinas, 2000, 159p. Tese (Doutor em Ciência de Alimentos) - Faculdade de Engenharia de Alimentos, Universidade Estadual de Campinas (UNICAMP).

[17] HOUGHTON, P. J.; ZARKA, R.; HERAS, B.; HOULT, J.R. Fixed oil of Nigella sativa and derived thymoquinone inhibit eicosanoid generation in leukocytes and membrane lipid peroxidation. Planta Medica, v. 61, n. 1, p. 33-36, 1995.

[18] IARC, Monographs on the evaluation of the carcinogenic risk of chemicals to humans. Allyl compounds, aldehydes, epoxides and peroxides, IARC, Lyon, France v. 36 , p. 267,1985 .

[19] ITO, Y.; TONOGAI, Y.; SUZUKI, H. Improved 4-aminoantipyrine colorimetry for detection of residual hydrogen-peroxide in noodles, fish paste, dried fish and herring roe. Journal of AOAC International, v. 64, n. 5, p. 1448-1452, 1981.

[20] JACKSON, P.; RICARDO, C. P. P. Cytochrome C aided resolution of Lupinus albus isoperoxidases in a cathodal polyacrylamide gel electrophoresis system. Analitical Biochemistry, v. 200, n. 1, p. 36-41, 1992.

[21] JOHANSSON, E.; MARKO-VARGA, G.; GORTON, L. Study of a reagent- and mediator-less biosensor for D-amino acids based on co-immobilized D-amino acid oxidase and peroxidase in carbon paste electrodes. Journal of Biomaterials Applications, v. 8, n. 2, p. 146-73, 1993.

[22] KHAN, A. A.; ROBINSON, D. S. Hydrogen donor specificity of mango isoperoxidases. Food Chemistry, v. 49, n. 4, p. 407-410, 1994.

[23] KOK; G. M.; HOLLER, T. P.; LOPEZ, M. B. Chemiluminescent method for determination of hydrogen-peroxide in ambient atmosphere. Environmental Science and Technology, v. 12, n. 9, p. 1072-1076, 1978.

[24] KOKÇAM, I.; NAZIROGLU, M. Antioxidants and lipid peroxidation status in the blood of patients with psoriasis. Clinica Chimica Acta, v. 289, n. 1-2, p. 23-31, 1999.
[25] LIAO, X-R; ZHU, X-C; HE, P-C. A cationic peroxidase from leaves of Vitis pseudoreticulata. Phytochemistry, v. 51, n. 1 , p. $143-145,1999$.

[26] LIN, Z-F; CHEN, L-H; ZHANG, W-Q. Peroxidase from Ipomoea cairica (L) SW. Isolation, purification and some properties. Process Biochemistry, v. 31, n. 5, p. 443-448, 1996.

[27] LÓPEZ-SERRANO, M.; ROS BARCELÓ, A. Purification and characterization of a basic peroxidase isoenzyme from strawberries. Food Chemistry, v. 55, n. 2, p. 133-137, 1996.

[28] McClEAR, B. V.; GLENNIE-HOLMES, M. Enzymatic quantification of (1-3) (1-4)- $\beta$-D-Glucan in barley and malt. Journal of the Institut of Brewing, v. 91, n. 2, p. 285-295, 1985.

[29] NAKAYAMA, T.; AMACHI, T. Fungal peroxidase: its structure, function, and application. Journal of Molecular Catalysis B: Enzymatic, v. 6, n. 3, p. 185-198, 1999.

[30] RAMAMURTHY, M. S.; USSUF, K. K.; NAIR, P. M.; THOMAS, P. Lignin biosynthesis during wound healing of potato tubers in response to gamma irradiation. Postharvest Biology and Technology, v. 18, n. 3, p. 267-272, 2000.

[31] ROS BARCELÓ, A.; MUÑOZ, R.; SABATER, F. Lupin peroxidase. I. Isolation and characterization of cell wallbound isoperoxidase activity. Physiology Plantarum, v. 71, n. 4, p. 448-454, 1987.

[32] ROS BARCELÓ, A.; ZAPATA, J. M.; CALDERÓN, A. A. Tissue-specific expression of peroxidase activity in seedless grapes (Vitis vinifera cv. Thompson and Flame). Revista Espanola de Ciencia y Tecnologia de Alimentos, v. 34, n. 2, p. 110-116, $1994 a$.

[33] SELLERS, R. M. Spectrophotometric determination of hydrogen-peroxide using potassium titanium (IV) oxalate. Analyst, v. 105, n. 1255, p. 950-954, 1980.

[34] SERGEYEVA, T. A.; LAVRIK, N. V.; RACHKOV, A. E.; KAZANTSEVA, Z. I.; PILETSKY, S. A.; ELSKAYA, A. V. Hydrogen peroxide - sensitive enzyme sensor based on pthalocyanine thin film. Analytica Chimica Acta, v. 391, n. 3, p. 289-297, 1999.

[35] SOARES, C. M. F.; SANTANA, M. H. A.; ZANIN, G. M.; CASTRO, H. F. Effect of poly (ethylene) glycol and albumin on the immobilization of microbial lipase and catalysis and catalysis in organic media. Química Nova, v. 26 , n. 6 , p. $832-838,2003$.

[36] SRIVASTAVA, O. P.; VAN HUYSTEE, R. B. An inter-relationship among peroxidase, IAA oxidase and polyphenoloxidase from plant cells. Canadian Journal of Botany, v. 55, n. 12 , p. 2630-2636, 1977.

\section{7 - AGRADECIMENTOS}

Os autores são gratos a CAPES pela bolsa de doutorado de H.P.F. Maciel e pelo apoio oferecido pela UNICAMP. 